\title{
MEDICALIZAÇÃO, DESMEDICALIZAÇÃO, POLÍTICAS PÚBLICAS E DEMOCRACIA SOB O CAPITALISMO
}

\author{
MEDICALIZATION, DEMEDICALIZATION, PUBLIC POLICIES \\ AND DEMOCRACY UNDER CAPITALISM \\ MEDICALIZACIÓN, DESMEDICALIZACIÓN, POLITICAS PÚBLICAS \\ Y DEMOCRACIA BAJO EL CAPITALISMO
}

\author{
Paulo Frazão ${ }^{1}$ \\ Marcia Michie Minakawa ${ }^{2}$
}

Resumo A expansão da influência da medicina sobre problemas sociais e questões morais tem sido objeto de intensas discussões, mas muitos especialistas reclamam que a análise tem perdido rigor. Neste ensaio, recuperamos os sentidos mais profundos do termo medicalização e discutimos duas hipóteses inter-relacionadas: se as políticas públicas com impacto positivo sobre os níveis de saúde populacional cumpririam um papel desmedicalizante e se o aprofundamento da democracia poderia ser considerado uma condição imprescindível para enfrentar os processos medicalizantes. Com base na literatura, identificam-se conceitos nucleares relacionados às principais forças motrizes dos processos de medicalização e também mudanças associadas ao controle aumentado sobre a natureza que modifica a vida como a conhecemos, e destaca-se o avanço da ordem econômica capitalista sobre outras esferas como o Estado e a comunidade. Diante deste contexto, argumenta-se que qualquer perspectiva desmedicalizante de longo alcance dependeria ao menos de duas hipóteses inter-relacionadas que correspondem ao modelo que orienta a resposta às necessidades de saúde e à força da democracia em seu duplo sentido, seja como categoria política capaz de colocar os setores majoritários da sociedade no centro das decisões do Estado, seja como categoria econômica capaz de alterar os efeitos econômicos do capitalismo nas relações Estado-sociedade.

Palavras-chave medicalização; saúde pública; política pública.
Abstract The expansion of the influence of medicine on social demands and moral issues has been the subject of intense discussions, but many experts claim that the analysis has lost rigor. By this essay, we recover the deeper senses of the term medicalization and discuss two interrelated assumptions: if public policies with a positive impact on the population health levels would meet a demedicalizing role and if the deepening of democracy could be considered an essential condition to face the medicalizing processes. We summarize core concepts related to the main driving forces of medicalization processes and also changes associated with increased control over nature transforming life as we know it, highlighting the advance of capitalist economic order on other spheres as the state and the community. We argue that any long-range demedicalizing perspective would depend at least two hypotheses interrelated, corresponding to the model that guides the response to health needs, and the strength of democracy in its double meaning, either as a politics category able to put the majority sectors of society at the heart of state decisions, either as an economic category able to change the economic effects of capitalism in the state-society relations.

Keywords medicalization; public health; public policy. 


\section{Introdução}

Necessidade de saúde é um conceito político, complexo, e carregado de valor. A avaliação da necessidade de saúde é um componente essencial do planejamento de serviços e programas de saúde pública; e a questão central pode ser formulada como 'necessidade para quê'. Em termos individuais, significa fazer uma avaliação para prescrever um tratamento; enquanto em termos populacionais, significa avaliar para adotar uma estratégia de saúde pública que pode ser uma intervenção destinada à promoção da saúde ou à prevenção de uma determinada doença ou à provisão de determinados serviços de saúde (Cowley, 2008). Em sentido mais amplo, necessidades de saúde transcendem as necessidades de tratamento clínico ou de serviços de saúde, e envolvem vulnerabilidades que expressam modos de vida e identidades. Podem ampliar-se, portanto, para o que é necessário para a saúde, sejam perspectivas distintas ligadas à determinação social (Stotz, Cecílio e Sevalho, 2016) e aos determinantes sociais, seja a ideia de projeto de felicidade e qualidade de vida em diálogo com interesses individuais de natureza estética, emocional e moral, entre outros (Ayres, 2002). Independentemente da finalidade, a avaliação da necessidade de saúde é sempre uma atividade complexa que requer a explicitação das condições sob as quais o conceito será operacionalizado.

Desde a segunda metade do século XX, a expansão da influência da medicina sobre problemas sociais e questões morais tem sido objeto de intensas discussões. Por diferentes razões, determinadas necessidades sociais passam a ser consideradas necessidades de saúde sob jurisdição da medicina, ou seja, necessidades de assistência médica. Conforme Murguía, Ordorika e Lendo (2016), cada vez mais, uma maior quantidade e diversidade de condições, comportamentos e experiências são categorizados como doenças ou distúrbios, e se juntam ao campo de conhecimento e do exercício de profissionais da biomedicina.

Desde a década de 1960, emerge a noção de medicalização. Ela é invocada nos debates da psiquiatria pelos autores Barbara Wootton e Thomas Szasz; e ganha corpo como objeto de estudo no campo da sociologia da saúde, com destaque para as publicações Medicine as an Institution of Social Control, de Irving Zola (1972); Nêmesis da Medicina: a expropriação da saúde, de Ivan Illich (1975); The discovery of hyperkinesis: notes on the medicalization of Deviant Behavior, de Peter Conrad (1975) e, por fim, várias obras de Michel Foucault.

A reflexão sobre os processos de expansão da jurisdição da profissão médica para novos domínios incidiu sobre fenômenos tão cruciais quanto diversos, como a psiquiatria e a saúde pública (Zola, 1972); as formas heteronômicas de produção dos cuidados de saúde (Illich, 1975); os problemas sociais como alcoolismo, hiperatividade e toxicodependência (Conrad, 1975); as formas de 
intervenção do Estado no corpo social, na força de trabalho, no espaço urbano visando o controle das epidemias (Foucault, 1977).

De fato, se, numa primeira vista, esses são alguns exemplos das principais questões abordadas, numa leitura mais profunda da contribuição de cada autor, podem se descortinar problemas mais complexos ligados à exacerbação do individualismo nas sociedades, à industrialização dos sistemas de produção e ao desenvolvimento da economia capitalista. Por certo, todos esses aspectos têm importantes implicações para a interpretação dos processos de medicalização no início do século XXI, mas é necessário distinguir as intervenções em saúde que têm por finalidade a recuperação e a proteção da saúde do indivíduo, das intervenções direcionadas para a melhoria dos níveis de saúde na população.

$\mathrm{O}$ mundo e a sociedade moderna rumo à pós-modernidade têm atravessado, nos planos político, econômico e cultural, mudanças intensas que não pouparam os indivíduos, independentemente do lugar onde vivem. Nesse sentido, uma primeira indagação é se as políticas públicas com impacto positivo sobre os níveis de saúde populacional cumpririam um papel desmedicalizante em relação às políticas voltadas à assistência individual. Além disso, um dos aspectos que têm caracterizado essas mudanças é a queda de regimes totalitários, que foram sendo substituídos por sistemas políticos de caráter democrático, que tinham como premissa promover garantias como a expansão dos direitos humanos, civis e políticos, a transparência dos atos de governo e a participação política dos cidadãos. Do exposto, decorre uma segunda questão conectada à primeira, isto é, se o aprofundamento da democracia poderia ser considerado uma condição imprescindível para enfrentar os processos medicalizantes.

Ao mesmo tempo, na primeira década do século XXI, especialistas têm chamado atenção para a falta de rigor e clareza e a excessiva abrangência conceitual no uso do termo 'medicalização' na produção científica (Nye, 2003; Davis, 2006; Rose, 2007; Camargo-Junior, 2013; Zorzanelli, Ortega e Bezerra Junior, 2014; Carvalho et al. 2015). Diante disso, recuperar os significados subjacentes às contribuições de Zola, Illich, Conrad e Foucault a fim de discernir os aspectos nucleares que movem os processos de medicalização, e cotejar com o debate atual relativo à biomedicalização pode ajudar a restabelecer o rigor e a precisão conceitual pleiteada pelos especialistas.

Assim, o objetivo do presente ensaio foi recuperar os sentidos do termo medicalização e discutir duas hipóteses inter-relacionadas: se as políticas públicas com impacto positivo sobre os níveis de saúde populacional cumpririam um papel desmedicalizante e se o aprofundamento da democracia poderia ser considerado uma condição imprescindível para enfrentar os processos medicalizantes.

Escrutinar as principais forças que têm impulsionado a expansão da medicina sobre diferentes problemas sociais e questões morais não é uma tarefa 
de simples sumarização. Exige reconhecer diferentes tradições de explicação sociológica, nas quais se localizam o legado de várias perspectivas, cada uma com suas formas de abordagem, ferramentas de análise e características próprias. De um lado, uma perspectiva mais internalista, cujos pesquisadores sustentam que para compreender o significado das ações humanas basta sistematizar o conteúdo das narrativas das pessoas e conectá-las aos ritos ou momentos de fruição coletiva; e de outro, uma tradição mais externalista, representada por pesquisadores que procuram relacionar o conteúdo ao contexto, interpretando o significado das ações com base em estruturas mais gerais ligadas ao mundo social ou econômico. E entre essas duas tradições, cumpre mencionar as teorias sociais que postulam a superação das dicotomias estrutura/agência, micro/macro, objetivismo/subjetivismo. Não reconhecer a legitimidade dessas perspectivas poderia levar a incoerências e impropriedades que resultariam sem efeito para recuperar o rigor e a precisão conceitual pleiteada pelos especialistas. Na primeira seção, apresenta-se o resultado do esforço de sumarização e destacam-se quatro forças subjacentes aos processos de medicalização: a indústria, as instituições, o Estado e a sociedade. Na segunda seção, sintetizam-se reflexões mais recentes sobre os motores que seriam responsáveis por permanências, mudanças e deslocamentos desses processos. Na última seção, discutem-se as perspectivas de (des)medicalização e o potencial da democracia.

\section{Forças subjacentes aos processos de medicalização}

\section{Indústria}

Uma primeira linha de argumentação propugna que, numa sociedade altamente industrializada, o grande motor para as mudanças seria a tecnologia, que provocaria transformações significativas nos aspectos pessoais, econômicos, sociais e culturais e impulsionaria os processos de medicalização (Zola, 1972). Tais mudanças subverteriam as instituições. As indústrias planejariam a sua produção a fim de maximizar o lucro e o Estado interviria no setor econômico para capitalizar e defender as indústrias. A análise tem por fundamento a crítica à cultura da classe média norte-americana da década de 1960, marcada pela desigualdade socioeconômica, o fascínio pela tecnologia, o culto ao individualismo e ao consumismo desenfreado (Slater, 1976). O ritmo acelerado das mudanças contemporâneas encontraria as pessoas totalmente despreparadas para enfrentá-las, o que geraria uma sobrecarga, tanto física quanto emocional, que acabaria levando as pessoas a se refugiarem nas drogas, no misticismo, no vandalismo, na violência não dirigida, e comprometeria a sua tomada de decisão, assim “(...) quanto maior o grau de mudança de vida, maior o risco de que a doença subsequente venha ser grave" (Toffler, 1970, p. 267). 
Sob essa perspectiva de valorização da tecnologia e da ciência como um progresso a ser alcançado, é que algumas instituições se encontrariam totalmente subvertidas pela lógica do capital. Ao tomar como exemplo a hipercinesia, Conrad (1975) mostrou como as indústrias farmacêuticas investiram no tratamento medicamentoso do problema. Ao financiarem conferências e a difusão de informações sobre critérios de diagnóstico e tratamentos, concorreram para legitimar o fenômeno como um distúrbio psiquiátrico infantil, e impulsionaram o Estado a investir em pesquisas e na implantação de clínicas pediátricas especializadas. Cabe destacar que o autor considerava que as ações das empresas farmacêuticas não eram ilimitadas, isto é, elas não poderiam coagir os pais a aceitarem determinada conduta, e ainda, só poderiam promover o tratamento do problema mediante a avaliação médica. Quando se refere ao contexto estadunidense, o autor menciona certas restrições ao citar instituições como o subcomitê do Congresso Americano que exercia algum grau de regulação das atividades das indústrias farmacêuticas no momento que fosse constatado abuso na venda de medicamentos psicoativos.

Menção à sociedade industrial também é feita por Illich $(1975 ; 1976)$, cuja reflexão é direcionada de forma preponderante aos países capitalistas avançados, no caso Estados Unidos e Inglaterra. O autor argumenta que por razões históricas, políticas e jurídicas não foi possível a emissão de dados sobre a avaliação do ato médico nos países como União Soviética, França, Itália ou Alemanha. Independentemente do modelo econômico, o Estado em si não é tomado pelo autor como uma entidade relevante para o processo de medicalização e configura-se apenas como uma arena na qual forças motrizes e atores fazem avançar tais processos.

\section{As instituições}

Para Illich (1976), a principal força motriz seria a elite médica, uma organização profissional com uma força equiparável a uma instituição tão antiga e tão importante quanto o Estado, capaz de exercer forte controle na ciência, na política, na economia e na sociedade. Na sua obra, a medicina exerceria um mandato tão imperativo frente às outras instituições a ponto de invadir campos que até então não lhe pertenciam. Seriam espaços privilegiados e disputados por outras instituições e atores; que nas mãos da medicina levariam a efeitos deletérios nos aspectos individual, social e econômico, e gerariam diferentes formas de iatrogênese legitimando as formas heteronômicas de produção da saúde.

Uma distinção conceitualmente relevante é a diferença entre medicalização como expansão do escopo e da relevância social da prática médica e a noção de poder médico que se refere ao domínio exercido por uma categoria profis- 
sional, seja na condução da assistência médica individual, seja nas prioridades e decisões de políticas de saúde (Broom e Woodward, 1996).

Conrad (1975) não faz uso do termo elite, mas parte da ideia de que as instituições são 'empreendedores morais' que transcendem o ambiente comum dos indivíduos, tomam decisões, emitem regras, evocam especialistas, convencem as pessoas sobre a necessidade moral de uma regra. Para ele, o ponto crucial é que a medicalização é atravessada por outros fatores. Além do controle médico profissional, existem instituições que orquestram o comportamento dos atores, no sentido do cálculo estratégico e da escolha mais racional ao ponderarem aspectos políticos e econômicos.

Num sentido amplo, as instituições podem ser concebidas como um conjunto de regras e convenções que orientam as normas e os procedimentos (Hall, Taylor, 2003, p. 196). Elas podem ser consideradas menos como rebatimento de outros fenômenos, e mais como um elemento central nas análises relativas aos arranjos políticos e sociais. Trata-se de uma perspectiva teórica na qual se busca decifrar como essas regras moldam os Estados nacionais, o funcionamento dos mercados, as políticas públicas e as estratégias das organizações e dos atores incluindo os resultados políticos decorrentes (Marques, 1997).

Essa linha reflexiva permite apontar que as instituições sociais, políticas e econômicas sustentadas em interesses, identidades e recursos de poder próprios, se organizam formalmente e assim exercem grande influência nos processos de medicalização.

\section{Estado}

A fim de identificar a gênese e as reconfigurações que as forças motrizes dos processos de medicalização atravessam até a contemporaneidade, Michel Foucault dirige o olhar para a Europa dos séculos XVII e XVIII num esforço de aproximação intensa com as instituições e os sujeitos envolvidos (Foucault, 1977). O autor descreve a medicina social como uma força portadora de conhecimentos específicos que assegurariam o funcionamento da sociedade moderna por meio de normas morais de conduta e prescrição de determinados comportamentos, principalmente sobre as questões relacionadas à higiene e à transmissão de doenças. Dessa forma, Foucault identifica um movimento de medicalização que se traduz por uma forma de biopoder.

O primordial era distribuir e organizar indivíduos nas cidades, manter os corpos em condições adequadas de higidez e aumentar a força útil com a finalidade de controlar os fatores que pudessem prejudicar a saúde do trabalhador, o que poderia comprometer os custos econômicos de uma nação. Concomitantemente, havia o intento de diminuir qualquer tipo de sublevação contrária às instituições. Sob este pano de fundo, o conhecimento produzido no âmbito da medicina social foi apropriado cada vez mais pela medicina, o 
que propiciou o fortalecimento da sua relação com o Estado e com o capitalismo, a ponto de se consolidar como uma importante estratégia biopolítica na contemporaneidade e ocupar um espaço privilegiado na governamentalidade do Estado (Foucault, 2004). O filósofo francês vai argumentar que a medicina se encontra agenciada por interesses econômicos e por táticas políticas que a legitimam como instituição que reproduz a lógica do capital, não apenas como objeto de consumo, mas também como objeto de sua reprodução.

Pode-se dizer que algumas instituições como a medicina e o Estado não assumem mais um lugar central de poder, mas seriam conduzidos por princípios e regras intrínsecos à ordem econômica do mercado capitalista. Portanto, o quê e a forma como o governo opera vão se combinar na noção de governamentalidade, termo cunhado pelo autor e que expressa a racionalidade que subjaz nas formas de governo. A governamentalidade é retratada em três aspectos: o primeiro seria um conjunto de instituições, procedimentos e táticas que consubstanciariam uma tecnologia disciplinar na forma de biopoder; o segundo corresponderia a um governo com um determinado tipo de poder, a biopolítica, que levou a uma perspectiva disciplinadora exercida sobre a população e, por fim, o terceiro ponto no qual o Estado não é detentor de poder, mas desdobramento de outros poderes: num primeiro momento guiado pela teoria do Direito, num segundo momento pela doutrina liberal, e num terceiro momento pela ordem neoliberal (Foucault, 2004).

Cada governamentalidade engendra diferentes formas de dominação, exploração e sujeição que exigem, por sua vez, diferentes formas de luta e de resistência. Lutas que ganham significado - ou seja, que só existem - quando os sujeitos se encontram livres. Para cada adversidade abre-se espaço para outros mecanismos de poder. Segundo Foucault (1995), o poder e as estratégias de luta estão encadeados entre si. O autor exemplifica as formas de resistência fundamentadas na atuação de grupos religiosos e da própria população quando reivindica seus direitos e sua autonomia decisória e se coloca contra a inflexibilidade da medicina (Foucault, 1984). Tal fato remete à ideia de liberdade que poderia ser concretizada com base na mobilização dos sujeitos e poderia se desdobrar em outras possibilidades de exercício político e econômico.

Foucault (2004) aprofunda a reflexão relativa às formas de controle sobre os indivíduos pelo Estado, alicerçadas no atravessamento de regras e princípios da economia capitalista, a ponto de o indivíduo se converter em um agente econômico. O homo oeconomicus (Foucault, 2004, p. 201) não tem a noção dos limites das transações econômicas, nem sabe por que persegue determinados interesses dentro da perspectiva da governamentalidade neoliberal. Age com comportamento egoísta, em prol de seu interesse econômico e com objetivo de potencializar suas capacidades e competências para o trabalho laboral (Foucault, 2004). 
As ideias elaboradas pelo filósofo francês, com base em sua vasta literatura, desvelam o Estado como uma importante força motriz imbuída de uma racionalidade do mercado capitalista sob a perspectiva neoliberal, que não vai intervir apenas nos processos econômicos, mas sobre a "trama e espessura da sociedade" para viabilizar a concorrência entre os mercados (Foucault, 2004, p. 199). Diante destas considerações, podemos concluir que é um governo que se reconhece e se mantém por meio de leis econômicas, e suplanta a visão tradicional que atribui ao Estado o monopólio de poder sobre os sujeitos e outras instituições. O autor aprofunda as suas reflexões no sentido de que há uma rede de poder articulada ao Estado, que acaba por atravessar toda estrutura social, pois o dilema do aparato estatal é vigiar a vida cotidiana dos sujeitos com o objetivo de disciplinar os comportamentos, hábitos e discursos. Segundo Foucault (1984, p. 281) “(...) governar um Estado significará, portanto, estabelecer uma economia no nível geral do Estado, isto é, ter em relação aos habitantes, às riquezas, aos comportamentos individuais e coletivos, uma forma de vigilância, de controle tão atenta quanto a do pai de família (...)". Um Estado eficiente na sua forma de governar, consequentemente, irá repercutir na conduta dos indivíduos, pois “(...) quando o Estado é bem governado, os pais de família sabem como governar suas famílias, seus bens, seu patrimônio e por sua vez os indivíduos se comportam como devem" (Foucault 1984, p. 281).

Zola (1972) também sugere o Estado como importante força motriz nos processos de medicalização, porém não de uma forma tão explícita e minuciosa como apresentada por Foucault. Ele faz referência ao sistema burocrático, que ganha significado nas vozes de Alvin Toffler e Philip Slater. A instituição estatal, na visão de Zola (1972), também opera em prol das indústrias, possui como meta o aumento do consumo de bens materiais e o avanço no setor econômico por meio da tecnologia.

Entretanto, existe uma clara limitação no trabalho de Zola (1972) no que diz respeito à descrição do papel do Estado frente à diversidade e complexidade da situação política, econômica e histórica dos anos 1970 e 1980. Aquele que busca uma reflexão sobre a complexidade desse contexto e sobre os principais vetores de ação do Estado, por meio e por fora do aparato burocrático, encontrará em Foucault, uma reflexão de maior densidade e envergadura.

\section{Sociedade}

Por fim, a sociedade é descrita como uma importante força motriz. Uns apontam a sociedade como um ambiente propício para efetivar a medicalização, enquanto outros descrevem os indivíduos e grupos sociais como articuladores dentro da sociedade: ora para efetivar, ora para resistir a estes processos. Determinados pesquisadores sustentam perspectivas nas quais a 
sociedade encontra-se totalmente subjugada ao individualismo e ao consumismo desenfreado (Zola, 1972) e às formas heteronômicas de produção da saúde (Illich, 1975, 1976), e outros, em contrapartida, trazem para a arena discursiva a mobilização dos sujeitos e de grupos sociais dentro da sociedade, seja no confronto ou resistência aos processos de medicalização (Foucault, 1995, 1984; Conrad, 1975).

Conrad (1975) articula as associações civis de defesa à noção de 'empreendedores morais' que atuariam em prol dos interesses de um grupo dominante, seja na política ou na economia; isto é, as associações não seriam um grupo solitário, mas a expressão da articulação de interesses entre atores; no que diz respeito à inclusão do fenômeno da hipercinesia como uma desordem de aprendizagem.

Essa perspectiva teve pouco relevo na reflexão de Zola (1972), para quem a possibilidade de as organizações sociais participarem de certas decisões estaria reduzida, pois prevaleceriam os interesses voltados à expansão da industrialização e do consumo de bens materiais. Assim, o autor coloca os homens em uma situação de fragilidade frente a uma sociedade complexa na qual predomina a superindustrialização.

Vale destacar que este arranjo descrito por Zola (1972) seria potencialmente alimentado pela própria sociedade, que teria por aspiração que certas decisões fossem centralizadas nas mãos de médicos, dada a crescente credibilidade deles para resolver um conjunto cada vez mais amplo de problemas em variados aspectos da vida. Essa afirmativa fortalece a perspectiva de que o processo de medicalização pode ser visto como uma via de mão dupla: ora impulsionado pelo potencial da medicina, ora pela aspiração da própria sociedade. Entretanto, em muitas situações, predomina a natureza privada da prática médica em que certas decisões são afastadas do escrutínio público ou determinadas informações são omitidas do público que poderia oferecer resistência aos procedimentos. Em outras situações, desloca-se o processo de tomada de decisão, e centraliza-se a aprovação de políticas públicas nas mãos de poucos profissionais e técnicos da área e, consequentemente, diminui-se a participação de organizações da base social. O que predomina na reflexão de Irving Zola é a natureza privada da medicina, justificada inicialmente pela ausência dos sujeitos em processos decisórios, numa sociedade centralizada na industrialização e também pela própria natureza da instituição médica que possui autonomia na pesquisa e no diagnóstico e tratamento das doenças.

Illich $(1975,1976)$ também busca olhar a sociedade pelo lado do consumismo e da superindustrialização, de modo que as pessoas estariam cada vez mais condicionadas a consumir bens e serviços, entre eles os cuidados médicos. E, para atingir tais perspectivas as instituições determinam o que é adequado ou não para os indivíduos, os induzem a se submeter a repetidas 
avaliações médicas que, muitas vezes, isentam as pessoas de qualquer tipo de responsabilidade política e social.

Estas certificações médicas abririam possibilidades para investimentos em escolas, no aumento de empregos e nas políticas públicas que visassem a novas intervenções terapêuticas. Como corolário, a sociedade estaria organizada como um grande hospital, o que tornaria as pessoas dependentes de práticas médicas. Por isso, a elite médica, na ótica de Illich, é um paradigma de uma instituição industrial, uma "estrutura política e social destruidora" (Illich, 1975, p. 9).

Foucault (1995) desloca a reflexão para forças motrizes que estariam situadas em aspectos mais profundos da sociedade, nos quais se encontram os sujeitos em constante formação com relação a si, aos outros (instituições e mercado, entre outros) e à própria sociedade. Em suma, o sujeito é um produto das relações de poder, uma conjugação de forças que, juntas, constituiriam indivíduos com rótulos de loucos, delinquentes, criminosos, entre outros.

A vantagem de desvelar as forças sob a ótica de Michel Foucault é a possibilidade de visualizar as tramas e as múltiplas linhas que fortalecem e sustentam o poder do Estado, da medicina, do poder judiciário, entre outras instituições. Para ele, o sujeito é o desdobramento dessas relações de poder e das relações do saber, relações que só existem quando os sujeitos são livres (Foucault, 1995). Ao tomar por referência várias publicações, podemos concluir que, para o autor, o significado de poder é distinto dos sentidos apresentados por Zola (1972) e Illich $(1975,1976)$ que associam o termo a uma ação vertical, de cima para baixo, uma repressão que comprometeria a autonomia e a liberdade dos sujeitos. Para Foucault (1984, p. 183), “(...) o poder deve ser analisado como algo que circula (...). Nunca está localizado aqui ou ali, nunca está nas mãos de alguns, nunca é apropriado como riqueza ou um bem. $\mathrm{O}$ poder funciona e se exerce em rede".

\section{Mudanças e deslocamentos}

Na sumarização apresentada na seção anterior foram destacados quatro conceitos nucleares representativos das principais forças motrizes (indústria, instituições, Estado e sociedade) que, segundo a literatura da segunda metade do século XX, têm impulsionado os processos de medicalização. Praticamente, todos os trabalhos que tematizam o assunto fazem referência a pelo menos um dos autores mencionados. A falta de rigor e a excessiva abrangência conceitual no uso do termo 'medicalização' na produção científica, reclamada por alguns pesquisadores, podem estar ligadas à riqueza das reflexões que atravessam diferentes dimensões e planos de interpretação nem sempre levados em consideração nas investigações relativas a processos de medicalização con- 
cretos e específicos. Contudo, é importante considerar que as forças motrizes mencionadas não são independentes umas das outras nos processos de (des) medicalização: elas estão em constante movimento entre si, condicionadas pelas transformações por que passam as relações Estado-sociedade.

Na primeira década do século XXI, a reflexão se renova nos termos apresentados a seguir. Para Conrad (2005), na medida em que novos estudos foram produzidos, ficou mais claro que a medicalização ultrapassou as fronteiras da psiquiatria e nem sempre foi produto do imperialismo médico (Illich, 1975), mas sim de forças sociais complexas. Conrad sugere três forças subjacentes: o poder e a autoridade da profissão médica, seja em termos de domínio profissional, empreendedorismo ou colonização médica (hipercinesia, menopausa, entre outros); os movimentos sociais e os grupos de interesse (alcoolismo, doença de Alzheimer etc.); e as atividades de caráter organizacional ou interprofissional, como foi o caso da obstetrícia e o desaparecimento das parteiras.

Para ele, as indústrias farmacêutica e de seguros, que jogaram um importante papel em muitos processos concretos, não foram consideradas determinantes na maioria das análises (Conrad, 2005). No final do século XX, houve uma profunda mudança na estrutura da medicina cuja consequência foi a erosão da autoridade médica e medidas de gestão da assistência para enfrentar questões de acesso e de controle de custos passaram a ter relevância. $\mathrm{O}$ médico passou a dividir a arena com outros atores que ganharam proeminência como os compradores, provedores, pagadores de serviços e os consumidores. As empresas de financiamento e de prestação de serviços de assistência médica, a indústria farmacêutica, e alguns tipos de médicos (por exemplo, cirurgiões plásticos) crescentemente passaram a ver grupos de pacientes como um mercado potencial. Além disso, novas fronteiras do conhecimento biomédico descortinaram-se com promessas de tecnologias farmacêuticas e genômicas que poderão revolucionar a assistência à saúde.

Para Clarke et al. (2003), essas mudanças e inovações técnico-científicas transformaram o fenômeno qualitativamente para um processo complexo, localizado em diferentes domínios e numerosos sítios, e multidirecional, reconstituído por formas sociais emergentes, e práticas cada vez mais enredadas, técnico-cientificamente na biomedicina. A clínica médica moderna erigida sob os marcos de Bichat e seus contemporâneos, passa a se subordinar crescentemente aos aspectos biológicos. Assiste-se a uma reconfiguração das organizações de produção, distribuição e gestão da informação e conhecimento relacionado à assistência à saúde (tecnologias de informação médica, sistemas integrados ou em rede de hospitais, clínicas, empresas de financiamento e prestação de serviços de saúde, indústrias de biotecnologia, equipamentos e materiais, práticas de grupo, o Estado etc.). As mudanças são cumulativas, se manifestam em novos procedimentos de diagnóstico e tratamento (com base na bioengenharia, genômica, proteômica, tecnologias de visualização e 
desenvolvimento de medicamentos assistidas por computador, telemedicina etc.), e têm alcançado um nível suficiente para produzir o deslocamento da medicalização para a biomedicalização. O manejo apropriado das enfermidades crônicas tem se tornado uma responsabilidade moral individual a ser assegurada por meio de acesso ao conhecimento, autovigilância, prevenção, avaliação e tratamento do risco, e o consumo de bens e serviços biomédicos, sob padrões influenciados pela moda e por celebridades em novas possibilidades corporais tornadas disponíveis por meio de aplicações da tecnociência, uma noção específica que concebe ciência e tecnologia como dois domínios intrinsecamente articulados (Latour, 1987). Novas identidades individuais e coletivas são também produzidas. De um ponto de vista mais geral, esse processo é expressão da dinâmica de expansão político-econômica e sociocultural do setor biomédico.

Clarke et al. (2003) destacam cinco processos. Em um plano mais geral, observa-se a constituição político-econômica do complexo de serviços técnicos e biomédicos, isto é, o complexo médico-industrial sustentado por políticas desenvolvimentistas do Estado da era da medicalização passa a ser substituído por um complexo de serviços técnicos e biomédicos, impulsionado por corporações multinacionais compatíveis com a globalização dos mercados. A assistência à saúde, antes provida por organizações da profissão médica, passa para o domínio de sistemas de assistência gerenciada altamente segmentados e a pesquisa, antes financiada diretamente pelo Estado, passa a depender da colaboração com a indústria e a ter como resultado conhecimentos de propriedade privada e processos e produtos mercantilizáveis.

Um segundo processo é o foco na saúde de cada um e na biomedicina do risco e da vigilância, ou seja, o conceito de doença em nível de órgãos, tecidos e células é recortado para o nível de genes, moléculas e proteínas.

Um terceiro aspecto é a natureza técnico-científica crescente das inovações e práticas da biomedicina, isto é, os recursos e registros antes isolados e remotos são crescentemente integrados em sistemas computadorizados em que a decisão clínica não é com base nas características do caso individual e de intervenções da era da medicalização (antibióticos, quimioterapia, radiação, transplantes etc.), e sim com base na evidência produzida pela meta-avaliação dos desfechos registrados em bancos de dados de sistemas de assistência gerenciada e intervenções biomédicas que lançam mão da manipulação genética, da nanociência e da bioengenharia.

Outra dinâmica são as transformações da produção e distribuição do conhecimento biomédico. O controle da profissão médica sobre o acesso ao conhecimento diminui. Diferentes formas de disseminação e consumo de informações se multiplicam principalmente pela rede mundial de computadores. Novas possibilidades de intervenção, antes lançadas apenas no âmbito da profissão médica, passam a ser impulsionadas por novos atores, como movimentos de 
portadores de doenças, consumidores, usuários de internet, propagandas de corporações farmacêuticas etc.

Por fim, observam-se mudanças do corpo humano para incluir novas propriedades e a produção de novas identidades técnico-científicas no plano individual e coletivo. Medicamentos e tratamentos padronizados aplicáveis a todos os casos daquela classe de doença passam a ser individualizados e personalizados conforme os anseios decorrentes de identidades específicas construídas por meios técnico-científicos.

A mudança da medicalização para a biomedicalização guarda relação com a mudança dos problemas da modernidade engendrados pela revolução industrial para os problemas da pós-modernidade ou modernidade tardia ligados à revolução técnico-científica. A biomedicalização decorre de um controle aumentado sobre a natureza externa (o mundo que nos cerca) destinado ao aproveitamento e transformação da natureza interna (processos biológicos das formas de vida humana e não humana), modificando a vida como a conhecemos. O processo tem um alcance mais amplo do ponto de vista institucional derivado de inovações propiciadas pela ciência da computação e da informação nos espaços de produção da assistência e do conhecimento biomédico. O âmbito de intervenção (escopo) inclui expansão conceitual e clínica que se expressa em mercantilização da saúde, práticas segmentadoras que implicam agenciamentos de espaços, pessoas e técnicas de provisão de assistência que não dependem de profissionais de saúde, mas são administradas pelas próprias pessoas. Criam-se novas identidades, que por sua vez engendram relações sociais biomedicalizadas (Clarke et al. 2003, p.165). As mudanças se manifestam principalmente no nível organizacional e institucional. Mediadas pela aplicação de tecnologias da computação e informação, geram novas formas sociais cujo processo vai além do determinismo tecnológico e assume como pressuposto que a ação humana e a tecnociência são co-constitutivas, ou seja, os trabalhadores e as pessoas em geral, tanto como pacientes quanto como provedores, negociam e respondem o tempo todo aos processos de biomedicalização, na tentativa de assimilar inovações técnico-científicas e novas formas organizacionais a fim de satisfazer suas necessidades. Para Clarke et al. (2003, p. 184), as mudanças são "mudanças de ênfase" e os processos de medicalização, tal como foram descritos, continuarão a exercer sua influência, que tende a ser desigual, tanto do ponto de vista temporal como do espacial, conforme a disponibilidade de novas abordagens e alternativas técnico-científicas, que num primeiro momento inclinam-se a alcançar apenas o mercado de consumidores mais afluentes e alargar a distância entre ricos e pobres.

Para Conrad (2005), houve um deslocamento das forças motrizes e assumiram proeminência a biotecnologia (a indústria farmacêutica e de biotecnologia tornam-se os principais atores no processo de medicalização); os consumidores (a propaganda não é dirigida apenas aos médicos, mas sobretudo aos pacientes 
como consumidores); e a assistência gerenciada que delibera sobre o tratamento ou o serviço que deve ser financiado. Com isso, o papel da profissão médica tem ocupado um lugar cada vez mais secundário.

Nesse sentido, o processo de medicalização passa a ser impulsionado mais pelos interesses comerciais e de mercado, do que pelas aspirações da profissão. Nesta arena com novos atores, a relação entre mudanças normativas e medicalização se dá em ambas as direções, isto é, a propaganda sobre um determinado medicamento (Viagra) pode desestigmatizar uma determinada condição (disfunção erétil), ao mesmo tempo em que a noção anterior sobre a condição é substituída por uma noção normalizada, que por sua vez gera uma demanda para o consumo do medicamento.

A ideia de que o processo de medicalização passa a ser impulsionado mais pelos interesses comerciais e de mercado do que pelas aspirações da profissão não é nova. Como foi apresentado na seção anterior, Foucault ao enunciar a racionalidade que subjaz nas formas de governo, mostrou que instituições como a medicina e o Estado, não mais representavam o centro do poder, e sim expressavam princípios e regras intrínsecos à ordem econômica do mercado capitalista (Foucault, 2004).

A consequência dessa racionalidade, conforme as ideias de Clarke et al. (2003), é a constituição político-econômica do complexo de serviços técnicos e biomédicos impulsionado por corporações multinacionais compatíveis com a globalização dos mercados; o predomínio de sistemas de assistência gerenciada altamente segmentados e a pesquisa dependente da colaboração com a indústria e de compromissos com processos e produtos mercantilizáveis. O papel da indústria, das instituições, do Estado e da sociedade continua presente nas mudanças e nos deslocamentos que expressam a reflexão na primeira década do século XXI, entretanto, menos como uma força determinante, e mais como entes, por meio dos quais interesses de ordem econômica são alcançados.

Também não é nova a noção de que a relação entre mudanças normativas e medicalização se dá em ambas as direções, isto é, entre o sujeito e a estrutura em que ambos interagem. Ao refletir sobre o atravessamento de regras e princípios da economia capitalista, a ponto de o indivíduo se converter em um agente econômico, Foucault ofereceu uma chave para desvelar interesses e comportamentos que se encontram dentro da trama da sociedade e que dão sustentação a essa racionalidade como uma substância constituinte. A natureza técnico-científica crescente das inovações e práticas da biomedicina vai criar condições para a instauração de mudanças significativas nas formas de vigilância, nos sistemas de decisão clínica, nas aspirações e nas identidades dos usuários. São transformações aceleradas nas características do mundo da vida com importantes implicações para as regras e os princípios que orientam nossa concepção de sociedade humana em decorrência dessa articulação intrínseca entre ciência e tecnologia. 
Ao escrutinar as principais forças que têm impulsionado a expansão da medicina sobre diferentes problemas sociais e questões morais, pode-se afirmar que essas forças operam processos em múltiplos níveis. Assim como esses processos engendram a (bio)medicalização, também são (re)produzidos e transformados por meio da (bio)medicalização ao longo do tempo. Com isso, resultam legítimas as perspectivas de interpretação sociológica mais internalista, mais externalista e aquelas que buscam articular ação humana e estrutura social. Como foi mencionado, essas forças não são independentes uma das outras nos processos de medicalização: elas estão em constante movimento entre si, condicionadas pelas transformações por que passam as relações Estado-sociedade.

Essas conexões ficam mais claras se olharmos para as mudanças que ocorrem na sociedade moderna, rumo à pós-modernidade. Desde os anos 1970, o mundo experimentou intensas mudanças nos planos político, econômico e cultural, que não pouparam os indivíduos, independentemente do lugar onde vivem.

No plano político, presenciou-se a queda de regimes totalitários, que foram substituídos por sistemas políticos de caráter democrático, que tinham como premissa promover garantias como a expansão dos direitos humanos, civis e políticos, um sistema político conduzido de forma transparente (accountability) e a participação política dos cidadãos.

Enquanto isso, no plano econômico, temos o fenômeno da globalização, em que os países se tornaram interdependentes entre si, com uma grande conexão entre as sociedades. Em suma, esse fenômeno resulta em agrupamentos de países e regiões (relativamente os mais ricos) que visam defender, explorar e isolar as vantagens competitivas. Com isso, há níveis crescentes da desigualdade social e exclusão, no que concerne às decisões políticas, de algumas nações que se encontram na periferia do capitalismo.

E, finalmente, no plano cultural, as transformações direcionaram para uma crescente 'homogeneização' das culturas, por meio da qual assiste-se a um processo progressivo de perda do caráter distintivo das formas de manifestação cultural (música, vestuário, culinária etc.), inclusive suas relações com as tradições regionais e nacionais que lhes deram origem.

Essas mudanças descritas por vários pesquisadores equivalem ao quadro segundo o qual Offe (1999) sustenta a hipótese de que essa nova conformação da sociedade, em direção a uma pós-modernização, não deve ser considerada apenas sob uma única perspectiva representada pelo Estado, ou pelo mercado, ou pela comunidade; nem mesmo pode ser tomada com fundamento em concepções baseadas na junção de apenas duas dessas entidades que exerceriam predomínio sobre a terceira.

A dominância de uma das esferas poderia dar origem a formas desbalanceadas de construção de instituições sociais e políticas representadas pelo estatismo excessivo, pelo império do mercado e pela exacerbação das identi- 
dades. O mesmo poderia ocorrer no caso da anulação de uma delas em favor das demais.

Essa linha aponta para a necessidade de combinar elementos do Estado, do mercado e da comunidade, pois cada um ativa uma determinada capacidade relevante para orientar a intervenção no mundo social e faz parte de uma intricada rede para garantir, em última instância, a coesão social. Seriam necessários, portanto, todos os três fundamentos da ordem social, num arranjo de modo a evitar que cada um deles se sobreponha aos outros, o que eliminaria sua influência (Offe, 1999).

Nesse sentido, o papel-chave para se obter um desenho institucional adequado do ponto de vista das relações Estado-sociedade deveria ser ocupado pelos cidadãos e suas próprias associações cívicas. O conhecimento especializado normativo é menos importante do que o julgamento público informado e o engajamento cívico deliberativo. Segundo Offe (1999, p. 131), o julgamento de um especialista diz respeito somente a "o que fazer e ao que não fazer". A linha que articula o Estado, o mercado e a comunidade é de natureza política, isto é, o enquadramento institucional de ação pública recente enfatiza a aproximação do associativismo cívico e do capital social; com objetivo de que os cidadãos se engajem em práticas associativas. Essas forças associativas seriam capazes de definir e redefinir de forma constante o arranjo de padrões institucionais mais adequado do que qualquer autoproclamado especialista ou protagonista intelectual de uma das doutrinas 'puras' de ordem social.

Frente a essas considerações, pesquisadores (Lavalle, Houtzager e Castello, 2006) têm se debruçado sobre a questão do aprimoramento da qualidade da democracia, isto é, têm se preocupado com as inovações institucionais, e têm como meta acolher atores de várias instâncias, como movimentos sociais, ONGs, associações; em espaços de participação e deliberação, sem a necessidade de uma relação institucionalizada, como a eleição. Portanto, a democracia deixou de ser um método restrito de seleção e legitimação de governos para perpassar a ampliação da participação dos cidadãos em processos decisórios.

Seja mudança de ênfase (Clarke et al., 2003), seja deslocamento de forças motrizes (Conrad, 2005), o que subjaz aos processos de medicalização, turbinados contemporaneamente pelas inovações da biomedicina, é o avanço da ordem econômica capitalista sobre outras esferas, como o Estado e a comunidade.

\section{Perspectivas de (des)medicalização e o potencial da democracia}

Diante desse contexto de acelerada penetração do capital em todas as esferas da vida social, é preciso indagar quais perspectivas restariam aos setores das sociedades democráticas, críticos a esse processo, e quais as implicações para estruturar as respostas às necessidades de saúde. 
Alguns especialistas reconhecem que a extensão e o grau em que qualquer processo de medicalização é sustentado ao longo do tempo variam de acordo com a autoridade social ou cultural, e o nível de mobilização das pessoas que aspiram ou que resistem e a eficácia percebida de qualquer intervenção médica. No final do século XX, houve novo potencial para desmedicalização decorrente tanto de mudanças sociais mais amplas, como da quantidade de processos de medicalização que se difundiram nas últimas três décadas (Ballard e Elston, 2005). Se o Estado e a sociedade, como forças motrizes, se transformam rapidamente frente as exigências de uma transição entre a modernidade e a pós-modernidade, não há como negar que temos um ambiente em constante mudança, o que o torna cada vez mais propício tanto para os processos medicalizantes quanto para os desmedicalizantes.

Nesse sentido, as perspectivas desmedicalizantes parecem apontar para duas hipóteses inter-relacionadas, isto é, a aceitação de uma dependeria da afirmação da outra. A primeira proposição decorre da noção de necessidade de saúde, como foi mencionado, um conceito político e carregado de valor, que torna a sua avaliação uma atividade complexa que exige considerar um amplo arco de problemas que abrangem desde os determinantes sociais até a ideia de projeto de felicidade e qualidade de vida, em diálogo com interesses de natureza estética, emocional e moral, entre outros. Em outros termos, um dos desafios estaria em como avaliar as necessidades de saúde a fim de produzir um arranjo equilibrado entre as necessidades coletivas e individuais, sem cair nas armadilhas do conceito positivo da saúde (Camargo-Junior, 2007). Outro desafio seria como distribuir os recursos a fim de assegurar tanto a implementação de estratégias de saúde pública em termos populacionais quanto às condições de provisão de determinados serviços e programas de saúde que possibilitassem acesso ao tratamento necessário.

A lógica que orienta a resposta aos problemas de saúde de uma população, num dado contexto histórico, corresponde a um determinado modelo de atenção que se expressa concretamente por meio do arranjo adotado para prover o grau de cobertura e de profundidade, tanto das ações de assistência individual quanto das ações coletivas setoriais e das ações intersetoriais que produzem impacto conhecido sobre a saúde da população. Esse arranjo varia bastante em cada país, mas, sem recorrer a esquematismos, pode-se identificar arranjos que expressam modelos mais liberais nos quais o papel do Estado é mínimo, voltado geralmente para a vigilância epidemiológica e sanitária; e arranjos nos quais é atribuído papel relevante ao Estado, tanto nestas áreas tradicionais como em outras áreas relacionadas à promoção da saúde, à prevenção de doenças e à assistência individual (modelos beveridgianos). Entre um polo e outro, existe uma variedade de situações que, nos países democráticos, resultam do embate entre as diferentes forças políticas que disputam o projeto de desenvolvimento social e econômico da sociedade em cada território. 
É reconhecido que a resposta a esses desafios pode envolver tensões entre abordagens medicalizantes, que veem a assistência médica individual como a principal solução para as necessidades de saúde, e abordagens que enxergam os cuidados médicos como um componente necessário, mas completamente insuficiente para enfrentá-las (Lantz, Lichtenstein e Pollack, 2007; Antunes, 2015). A elevação da morbimortalidade por doenças crônicas não transmissíveis reforçou a consciência das limitações dos serviços de saúde e a necessidade de considerar (Alsthon e Seymour, 1988) a noção de que a causa das enfermidades nos indivíduos não é a mesma que a causa da incidência das doenças nas populações (Rose, 1985). Decorre disso a distinção entre duas abordagens: uma mais ampla, na qual identificam-se determinantes sociais associados a menores níveis de saúde e formulam-se estratégias de saúde pública dirigidas à população como um todo; e outra mais específica, voltada à identificação de indivíduos susceptíveis e expostos a riscos, e à adoção de medidas para protegê-los. Se os determinantes econômicos e sociais são os determinantes primários da doença, as medidas para enfrentá-los deveriam ser políticas econômicas e sociais (Rose, 1992).

Entretanto, redirecionar as estratégias de saúde pública para as estruturas sociais da sociedade não representaria um retorno às suas origens? (Awofeso, 2004). E uma volta ao imperialismo sanitário que marcou as ações de saúde pública no passado? (Camargo-Junior, 2013). Além da rejeição às soluções impostas pela velha Saúde Pública, em favor do consentimento informado, outra exigência crucial do presente é a busca do melhor arranjo para prover o grau de cobertura e de profundidade tanto das ações de assistência individual quanto das ações coletivas setoriais e das ações intersetoriais que produzem impacto conhecido sobre a saúde da população. Entretanto, que outras condições seriam necessárias para possibilitar um contexto mais propício aos processos desmedicalizantes na dinâmica contemporânea?

Sem pretender explorar todas as condições, uma segunda hipótese interrelacionada à primeira (correspondente ao conceito de necessidade de saúde e sua implicação para a produção de um arranjo no qual a assistência médica individual não seja considerada a principal solução), decorre do avanço da ordem econômica capitalista sobre o Estado e a sociedade. Como foi mencionado, a predominância ou a anulação de uma esfera, em relação às demais, ameaça, em última instância, a coesão social.

Assim, uma condição importante para assegurar os três fundamentos da ordem social, num arranjo de modo a evitar que cada um deles se sobreponha aos outros e elimine sua influência, é compreender que se de um lado o capitalismo exerce um amplo papel, seja como um sistema de produção, seja como uma forma de sociedade na qual o controle sobre o capital e os meios de produção concentram-se nas mãos de uma pequena parcela da população correspondente aos proprietários, de outro lado, sempre há recursos que as 
comunidades detêm que podem ser mobilizados como fonte de resistência e contra-hegemonia.

Para alguns autores, o capitalismo adquiriu tamanha proeminência que pode ser considerado uma metainstituição, isto é, uma estrutura que modela o conjunto de valores, regras e procedimentos que caracterizam as demais instituições e as relações entre os indivíduos no âmbito do Estado e da sociedade. Para eles, somente a democracia, igualmente por seu atributo metainstitucional, seria capaz de desafiar e impor constrangimentos aos imperativos econômicos derivados dessa estrutura (Howlett, Ramesh e Perl, 2009)

Como metainstituição, o capitalismo é sustentado por um conjunto de crenças e práticas centrado no pressuposto da primazia do indivíduo na sociedade. As experiências de uma economia política de orientação estatal sob os marcos do socialismo ou do comunismo não foram suficientemente dinâmicas para resistir à estagnação econômica e, no final do século XX, quase todos os países do mundo são capitalistas, o que configura um quadro no qual destacam-se inúmeros arranjos dos respectivos sistemas de produção e formas de sociedade.

Essa ampla variação depende em grande medida do tipo de liberalismo econômico que cada país adota. O liberalismo é orientado pela visão de que todos gozam de direitos naturais inalienáveis, como, por exemplo, o direito à propriedade; e de que esses direitos devem ser protegidos contra a intromissão de outras instituições como o Estado, a Igreja e os sindicatos. Trata-se fundamentalmente de uma teoria do mercado na qual se pode atribuir diferentes responsabilidades ao Estado. Responsabilidades que vão desde um papel limitado às funções consideradas essenciais, como segurança e justiça, compromissos associados com a provisão de bens públicos puros que os mercados não conseguem realizar, até uma visão que reconhece um papel corretivo para atuar em qualquer atividade na qual o mercado não assegure a produção, distribuição e consumo de bens e serviços de modo a suprir as necessidades de toda a população (Howlett, Ramesh e Perl, 2009).

Entretanto, a ideia do liberalismo serviu a objetivos muito maiores do que se esperavam dos seus princípios originais, ao penetrar no discurso político moderno não apenas como um conjunto de ideias para limitar o poder do Estado, mas também como um substituto da democracia, ou seja, um meio de conter as revoluções em andamento ao não permitir que ultrapassassem os limites aceitáveis. O capitalismo propiciou a redefinição da democracia e sua redução ao liberalismo na medida em que a democracia liberal busca deixar intocadas várias áreas de nossa vida cotidiana não sujeitas à responsabilidade democrática, mas governadas pelos poderes da propriedade, pelas leis do mercado e pelo imperativo da maximização do lucro. As sociedades liberais capitalistas modernas pregam a separação da esfera econômica, de modo a 
proteger a propriedade e o mercado e mantê-los invulneráveis ao poder democrático (Wood, 2003).

Assim, a tarefa nas sociedades democráticas contemporâneas imersas numa realidade complexa e em mutação seria impedir que a democracia liberal hegemonize o campo democrático, ao limitar o exercício de direitos ao domínio da esfera política e civil. Seria necessário impedir retrocessos, e avançar não apenas em concepções mais democráticas de representação e novos modos de participação e autonomia, mas sobretudo na recuperação dos poderes perdidos para a economia, na conquista dos direitos econômicos, e em mecanismos alternativos ao mercado para regular a produção social.

Neste contexto, somente a democracia pode permitir que os segmentos mais fracos da sociedade tenham algum controle sobre o Estado, sobre o funcionamento dos mercados e sobre os efeitos adversos da propriedade capitalista dos meios de produção. Apenas ela oferece um mecanismo político que pode alterar os efeitos econômicos do capitalismo numa perspectiva anticapitalista, capaz de estruturar como metainstituição, uma barreira a sua lógica totalizadora e ao seu poder coercitivo que o leva a se expandir e intervir em todos os aspectos da vida social (Howlett, Ramesh e Perl, 2009). Neste ponto, Wood (2003) sugere que a democracia precisa ser pensada não apenas como categoria política, mas sobretudo como categoria econômica a fim de sujeitar a produção à responsabilidade social e viabilizar uma redistribuição mais equitativa dos meios de produção.

Diante do exposto e ainda que o presente ensaio tenha alcançado mais a indicação dos tópicos que conferem as condições de possibilidade para a admissão das hipóteses apresentadas do que desenvolvido, de um modo sistemático, todas as proposições e argumentos necessários, sustenta-se que qualquer perspectiva desmedicalizante de ampla envergadura e longa duração dependeria ao menos de duas hipóteses inter-relacionadas, correspondentes ao modelo que orienta a resposta às necessidades de saúde, e à força da democracia em seu duplo sentido, seja enquanto categoria política capaz de colocar os setores majoritários da sociedade no centro das decisões do Estado, seja como categoria econômica capaz de alterar os efeitos econômicos do capitalismo nas relações Estado-sociedade. Sem considerar essa profunda conexão, o campo prosseguiria escancarado aos processos medicalizantes.

\section{Considerações finais}

Os achados da pesquisa evidenciaram que a proposta do NASF ainda enfrenta dificuldades e desafios para que se concretize como objeto de transformação das práticas de saúde. Foram evidenciadas compreensão dual sobre o 
trabalho do NASF e sua forma de atuação. Questões referentes à infraestrutura, à valorização profissional e à gestão do trabalho também foram apontadas como obstáculos para a efetivação do apoio matricial. As características mais relevantes do estudo refletem a necessidade de maior proximidade na organização do trabalho entre equipes de referência e de apoio, bem como a revisão das questões estruturais e da valorização profissional. Estas barreiras indicam dificuldades de ação com base nas prerrogativas do apoio matricial.

Iniciativas que objetivem superar tais dificuldades devem ser viabilizadas. Para tanto, sugere-se o fortalecimento dos mecanismos da educação permanente em saúde, de forma a contemplar a metodologia do apoio matricial. Também é necessário maior sensibilização e comprometimento dos gestores em direção à superação dos problemas estruturais e organizacionais encontrados na prática cotidiana da APS. Por fim, reflete-se que as incompreensões ao caráter inovador do apoio matricial e as dificuldades estruturais não são indicativos da inefetividade do NASF, pelo contrário, apontam desafios ainda persistentes que necessitam ser superados em direção a uma APS abrangente e resolutiva.

\section{Colaboradores}

Marcia Michie Minakawa participou da concepção, elaboração e execução do projeto; coleta, fichamento e interpretação do material e escrita do artigo. Paulo Frazão participou da concepção, elaboração do projeto, interpretação do material, escrita e revisão crítica do artigo.

Resumen La expansión de la influencia de la medicina sobre problemas sociales y cuestiones morales ha sido objeto de intensas discusiones, pero muchos expertos reclaman que el análisis ha perdido rigor. En este ensayo, recuperamos los sentidos más profundos del término medicalización y discutimos dos hipótesis interrelacionadas: si las políticas públicas con impacto positivo sobre los niveles de salud poblacional cumplieran un papel desmedicalizante y si la profundización de la democracia podría considerarse una condición imprescindible para enfrentar los procesos medicalizantes. Con base en la literatura, se identifican conceptos nucleares relacionados a las principales fuerzas motrices de los procesos de medicalización y también cambios asociados al control creciente sobre la naturaleza que modifica la vida como la conocemos, y se destaca el avance del orden económico capitalista sobre otras esferas como el Estado y la comunidad. En este contexto, se argumenta que cualquier perspectiva desmedicalizante de largo alcance, dependería al menos de dos hipótesis interrelacionadas que corresponden al modelo que orienta la respuesta a las necesidades de salud, y a la fuerza de la democracia en su doble sentido, sea como categoría política capaz de colocar a los sectores mayoritarios de la sociedad en el centro de las decisiones del Estado, sea como categoría económica capaz de alterar los efectos económicos del capitalismo en las relaciones Estado-sociedad.

Palabras clave medicalización; salud pública; política pública.

\section{Notas}

${ }^{1}$ Universidade de São Paulo, Faculdade de Saúde Pública, Departamento de Prática de Saúde Pública, São Paulo, SP, Brasil. 
<pafrazao@usp.br>

Correspondência: Universidade de São Paulo, Faculdade de Saúde Pública, Departamento de Prática de Saúde Pública, Av. Dr. Arnaldo, 715, Cerqueira Cesar, CEP 01246-904, São Paulo, SP, Brasil.

${ }^{2}$ Universidade de São Paulo, Faculdade de Saúde Pública, São Paulo, SP, Brasil.

$<$ marciaenf@usp.br>

${ }^{3} \mathrm{Na}$ obra $\mathrm{O}$ nascimento da clínica, Michel Foucault argumenta que com o avanço dos conhecimentos e dos recursos tecnológicos da anatomopatologia, há uma mudança no exercício da clínica e uma clivagem entre o doente e a doença, na qual a última adquire novas espacializações propiciando a medicalização de novos territórios.

${ }^{4}$ Autores como Anthony Giddens (Central problems in social theory), Pierre Bourdieu (Coisas ditas), Jürgen Habermas (A lógica das ciências sociais), entre outros, têm chamado a atenção para os problemas entre estrutura e agência na teoria social. Com base na noção de que tomar um dos polos como explicativo do outro tem limitado o desenvolvimento da teoria social, postula-se a necessidade de articular o plano das estruturas coletivas que informam padrões institucionalizados de relações com o plano da conduta individual cotidiana e de seus motores subjetivos que orientam a ação.

${ }^{5}$ Desde a segunda metade dos anos 1970 até o final do século XX ocorreram, em um grande número de países, vários exemplos de transições para a democracia, começando pelos países do sudoeste da Europa, passando pela América Latina, alcançando o Leste Europeu e também a Ásia.

${ }^{6} \mathrm{O}$ termo é usado para destacar diferentes identidades que caracterizam comunidades e grupos sociais específicos no interior de uma mesma sociedade.

${ }^{7}$ Componente necessário inclusive para o desenvolvimento de propostas desmedicalizantes de assistência à saúde individual como, por exemplo, a estratégia do acolhimento realizado por equipes multiprofissionais em unidades de atenção primária, na qual a escuta, a avaliação de risco/vulnerabilidade, a orientação, a resolução de problemas e o cuidado fazem parte do 'campo de competência' de todos os profissionais (Tesser, Neto e Campos, em "Acolhimento e (des)medicalização social: um desafio para as equipes de saúde da família") e a crítica à gestão do cuidado em saúde frente aos processos de (des) medicalização (Gustavo C. Matta).

${ }^{8}$ No sentido gramsciano, conforme Carlos Nelson Coutinho (Gramsci: um estudo sobre seu pensamento político).

${ }^{9}$ A esse respeito, ver capítulo 5, "Institutions for high-quality growth", em Dani Rodrik (One economics, many recipes globalization, institutions, and economic growth).

${ }^{10}$ Contribuições como a de Benjamín Arditi et al. ("Democracia post-liberal? El espacio político de las asociaciones") oferecem elementos sobre o aprofundamento das tensões entre o liberalismo e a democracia em decorrência do alargamento do protagonismo de movimentos, associações e grupos de interesse.

${ }^{11}$ Ellen Meiksins Wood faleceu em 2016. Ao examinar as tensões entre a democracia e o capitalismo, ela abriu vários caminhos para pensar as instâncias, as modalidades e as estratégias necessárias para enfrentar os imperativos do mercado. Algumas reflexões 
podem ser encontradas em Boaventura de Sousa Santos (Democratizar a democracia: os caminhos da democracia participativa) e Luis Felipe Miguel (Utopias do pós-socialismo: esboços e projetos de reorganização radical da sociedade).

\section{Referências}

ALSTHON, John; SEYMOUR, Howard. The new public health: the Liverpool Experience. Philadelphia: Open University Press; 1988.

ANTUNES, José L. F. Desigualdades em saúde: entrevista com Nancy Kriger. Tempo Social: Revista de Sociologia da USP, São Paulo, v. 27, n. 1, p.177-194, 2015.

AWOFESO, Niyi. What's New About the "New Public Health"? American Journal of Public Health, Washington, DC, v. 94, n. 5, p. 705-709, 2004.

AYRES, José R. C. M. Conceptos y prácticas en salud pública: algunas reflexiones. Revista de la Facultad Nacional de Salud Pública, Medellin, v. 20, n. 2, p. 67-82, 2002.

BALLARD, Karen; ELSTON, Mary A. Medicalisation: a multi-dimensional concept. Social Theory \& Health, London, v. 3, n. 3, p. 228-241, 2005.

BROOM, Dorothy H.; WOODWARD Roslyn V. Medicalization reconsidered: toward a collaborative approach to care. Sociology of Health a Illness, Oxford, v. 18, n. 3, p. 357-378, 1996.

CAMARGO-JUNIOR, Kenneth R. As armadilhas da "Concepção Positiva de Saúde". Physis: Revista de Saúde Coletiva, Rio de Janeiro, v. 17, n. 1, p. 63-76, 2007.

CAMARGO-JUNIOR, Kenneth. Medicalização, farmacologização e imperialismo sanitário. Cadernos de Saúde Pública, Rio de Janeiro, v. 29, n. 5, p. 844-846, 2013.

CARVALHO, Sergio R. et al. Medicalização: uma crítica (im)pertinente? Physis: Revista de Saúde Coletiva, Rio de Janeiro, v. 25, n. 4, p. 1.251-1.269, 2015.
CLARKE, Adele E. et al. Biomedicalization: technoscientific transformations of health, illness, and U.S. Biomedicine. American Sociological Review, Washington, DC, v. 68, n. 2, p. 161-194, 2003.

CONRAD, Peter. The discovery of hyperkinesis: notes on the medicalization of deviant behavior. Social Problems, Oxford, v. 23, n. 1, p. 12-21, 1975.

CONRAD, Peter. The shifting engines of medicalization. Journal of Health and Social Behavior, Washington, D.C., v. 46, n. 1, p. 3-14, 2005.

COWLEY, Sarah. Community Public Health in policy and practice: a sourcebook. 2. ed. Oxford: Elsevier, 2008.

DAVIS, Joseph E. How medicalization lost its way. Society, New Brunswick, v. 43, n. 6, p. 51-6, 2006.

FOUCAULT, Michel. Historia de la medicalización. Educación Médica y Salud, Washington, D.C., v. 11, n. 1, p. 3-25, 1977.

FOUCAULT, Michel. Microfísica do poder. 4. ed. Rio de Janeiro: Graal, 1984

FOUCAULT, Michel. O nascimento da biopolítica. São Paulo: Martins Fontes, 2004.

FOUCAULT, Michel. Sujeito e poder. In: DREYFUS, Hubert L.; RABINOW, Paul. Michel Foucault: uma trajetória filosófica - para além do estruturalismo e da hermenêutica. Rio de Janeiro: Forense Universitária, 1995. p. 231-249.

HALL, Peter A.; TAYLOR, Rosemary C. R. As três versões do neo-institucionalismo. Lua Nova, São Paulo, n. 58, p. 193-223, 2003.

HOWLETT, Michael; RAMESH M; PERL, Anthony. Studying public policy: policy cycles 
and policy subsystems. Toronto: Oxford University Press, 2009.

ILLICH, Ivan. Nêmeses da medicina: a expropriação da saúde. 3. ed. Rio de Janeiro: Nova Fronteira, 1975.

ILLICH, Ivan. Limits to medicine medical nemesis: the expropriation of health. Toronto: Mario Boyars London, 1976.

LANTZ, Paula M.; LICHTENSTEIN, Richard L.; POLLACK, Harold A. Health policy approaches to population health: the limits of medicalization. Health Affairs, Bethesda, v. 26, n. 5 , p. $1.253-1.257,2007$

LATOUR, Bruno. Science in action how to follow scientists and engineers through society. Cambridge: Harvard University Press, 1987

LAVALLE, Adrián G.; HOUTZAGER, Peter P.; CASTELLO, Graziela. Democracia, pluralização da representação e sociedade civil. Lua Nova, São Paulo, v. 67, p. 40-103, 2006.

MARQUES, Eduardo C. Notas críticas à literatura sobre Estado, políticas estatais e atores políticos. Revista Brasileira de Informação Bibliográfica em Ciências Sociais, Rio de Janeiro, n. 43, p. 67-102. 1997.

MURGUÍA, Adriana; ORDORIKA, Teresa; LENDO, León F. El estudio de los procesos de medicalización en América Latina. História, Ciências, Saúde: Manguinhos, Rio de Janeiro, v. 23, n. 3, p. 635-651, 2016.

NYE, Robert A. The evolution of the concept of medicalization in the late twentieth century. Journal of History of the Behavioral Sciences, New York, v. 39, n. 2, p. 115-129, 2003.

OFFE, Clauss. A atual transição da história e algumas opções básicas para as institui- ções da sociedade. In: PEREIRA, Luiz C. B.; WILHEIM, Jorge; SOLA, Lourdes. Sociedade e Estado em transformação. São Paulo: Unesp; 1999. p. 119-146.

ROSE, Geoffrey. Sick individuals and sick populations. International Journal of Epidemiology, London, v. 14, n. 1, p. 32-38, 1985.

ROSE, Geoffrey. The strategy of preventive medicine. Oxford: Oxford University Press, 1992.

ROSE, Nikolas. Beyond medicalization. Lancet, London, v. 369, n. 9.562, p. 700-702, 2007.

SLATER, Philip. A busca da solidão. Rio de Janeiro: Zahar, 1976.

STOTZ, Eduardo N.; CECÍlIO, Luiz C. O.; SEVALHO, Gil. Necessidades de Saúde: conceito, valor e política. Intervozes: Trabalho, Saúde e Cultura, Petrópolis, v. 1, n. 1, p. 66-75, 2016.

TOFFLER, Alvim. O choque do futuro. Rio de Janeiro: Record, 1970

WOOD, Ellen M. Democracia contra o capitalismo: a renovação do materialismo histórico. São Paulo: Boitempo, 2003.

ZOLA, Irving K. Medicine as an institution of social control. The Sociological Review, London, v. 20, n. 4, p. 487-504, 1972.

ZORZANELLI, Rafaela T.; ORTEGA, Francisco; BEZERRA JUNIOR, Benilton. Um panorama sobre as variações em torno do conceito de medicalização entre 1950-2010. Ciência e Saúde Coletiva, Rio de Janeiro, v. 19, n. 6, p. 1.859-1.868, 2014.

Recebido em 21/11/2016. Aprovado em 15/08/2017.

\section{Errata}

No artigo “MEDICALIZAÇÃO, DESMEDICALIZAÇÃO, POLÍTICAS PÚBLICAS E DEMOCRACIASOBOCAPITALISMO", autoria de Paulo Frazão e Marcia Michie Minakawa, comnúmero deDOI: 10.1590/1981-7746-sol00123, publicado no periódico Trabalho, Educaçãoe Saúde, v. 16, n. 2, p. 407-430, a seção do texto intitulada “Considerações Finais" deve ser suprimida, pois não é integrante do artigo em questão. 